\title{
Application of the nanoindentation technique for the characterization of varved clay
}

https://doi.org/10.1515/geo-2018-0071

Received May 12, 2018; accepted Dec 07, 2018

\begin{abstract}
Nanoindentation is a test carried out in a small scale, during which a rigid indenter (of known hardness and geometry) is pressed into the tested material. The results of the test are the load and unload curves, from which the hardness and elastic modulus values can be calculated. In the case of a material characterized by high heterogeneity (like soil - composed of grains and particles of different size and mineral composition), the use of multiple nanoindentation on a predefined grid (Grid Indentation Technique) is reasonable. It allows for the determination of the morphology of the material in a selected scale of observation. In the study, nanoindetation tests were performed on samples of varved clay - soil composed of two alternately arranged layers - occurring near the city of Bełchatów in central Poland. Due to the layered structure of the material, the tests were carried out for both layers separately. The outcomes show that there are significant differences in the values of their mechanical properties. Application of the deconvolution technique also allowed for the estimation of the number of components of both layers and their mechanical properties.
\end{abstract}

Keywords: Nanoindentation, hardness, elastic modulus, morphology, GIT, deconvolution, varved clay

\section{Introduction}

Varved clay is a clayey sedimentary soil with a visible layering, which is formed in glacial lakes as a result of periodical melting of a glacier. It is composed of two alternately repeated layers: dark (silty-clayey) and bright (sandy-silty). Changes in sedimentation conditions results in the variability of the layers in terms of composition and thickness [1]. A consequence of the formation process is a multi- scale structure of the soil. Examinations of the properties of varved clays from different parts of the world are presented in [2-5]. The property that effects the layered structure of the clay is the anisotropy of the mechanical behavior of the material. Not taking this into account in geotechnical engineering may lead to some errors. Works related to constructions made in varved clays are [6-8]. However, in view of the complex nature of varved clay, testing and modelling its mechanical behavior is not a trivial issue. A comprehensive study on the assessment of the strength of varved clay, as well as its modelling were previously introduced by the author in [9]. The paper presents a macroscopic approach in which the material is considered as an anisotropic unity. Another approach is a micromechanical one in which the parameters of the microstructure are determined, which allows a prediction of the macroscopic properties of the material. However, in this case a proper description of the microstructure of the material can be seen to be the most significant.

Nanoindentation is a hardness test performed in a small scale. This technique allows for the determination of the mechanical properties of materials, such as hardness, indentation modulus and elastic modulus [10]. The application of nanoindentation to geomaterials was presented e.g. in [11-13]. In the paper, this procedure is used for characterization of varved clay in the nano-scale. The article focuses on varved clay occurring near the city of Bełchatów in central Poland. First, grid nanoindentation measurements were performed for both layers separately. Next, the deconvolution technique was used for separation of the material phases with respect to their mechanical properties. The technique allowed for the determination of a number of components of both layers and their mechanical properties. The work is a contribution in attempting to understand the mechanical behavior of the soil.

\section{Nanoindentation technique}

^Corresponding Author: Matylda Tankiewicz: Department of Civil Engineering, Wroclaw University of Science and Technology, Wroclaw, 50-370, Wybrzeże Wyspiańskiego 27, Poland; Email: matylda.tankiewicz@pwr.edu.pl; Tel.: +48 713203294
In the nanoindentation test a rigid indenter (of known hardness and geometry) is pressed into the tested mate- 
rial with a given force, which results in increase in depth of indentation. After the test, an imprint with a size depending on the hardness of the material remains in the sample. During the indentation, values of load $\mathrm{P}$ and depth $\mathrm{h}$ are recorded and the main outcome of the test are the P-h curves - see Figure 1. Analysis of the results allows for the determination of the micromechanical properties of the tested material: hardness, indentation modulus and elastic modulus. This technique was described in detail by Fischer-Cripps [14].

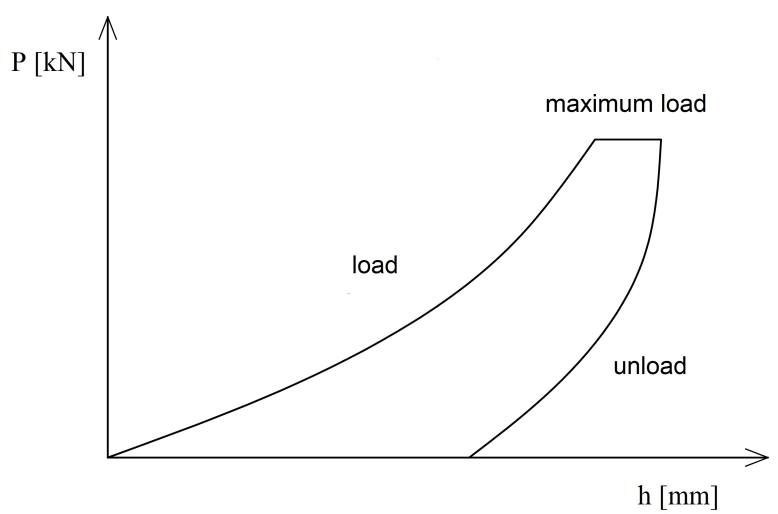

Figure 1: Load versus indentation depth curve.

The hardness $H_{I T}$ of the medium is defined as the ratio of the maximum force $P_{\max }$ to the contact surface (of the indenter and the sample) $A$ at the highest depth and force:

$$
H_{I T}=\frac{P_{\max }}{A},
$$

where size $A$ is defined as a function of the maximum indentation depth $\mathrm{h}_{\max }$ [15].

The indentation module $\mathrm{M}_{I T}$ is determined using the Sneddon solution [16], which describes the relationship between force and depth when pressing a rigid element into an elastic half-space. For the Berkovich tip (tree-sided pyramid), it is determined from the equation:

$$
M_{I T}=\frac{S}{2 \beta} \frac{\sqrt{\pi}}{\sqrt{A}}
$$

where $S$ is the slope of the unloaded curve, $A$ is the contact surface and $\beta$ is the dimensionless coefficient.

The elastic modulus $E_{I T}$ is determined by using the solution of the contact issue, presented by Hertz [17], from the equation:

$$
\frac{1}{M_{I T}}=\frac{\left(1-v^{2}\right)}{E_{I T}}+\frac{\left(1-v_{i}^{2}\right)}{E_{i}},
$$

where $E_{i}$ and $v_{i}$ are the elastic modulus and Poisson's ratio of the indenter, respectively, and $v$ and $E_{I T}$ are the param- eters of the tested material. Determination of modulus $E_{I T}$ requires the assumption of Poisson's ratio $v$.

In the case of materials characterized by high heterogeneity in micro and nano-scale, the use of the so-called Grid Indentation Technique (GIT) allows for the determination of the morphology of the material in a selected scale of observation [18]. In this approach, a large number of tests are made on the predefined grid. If the grid size and indentation depth are chosen properly, statistical techniques may be applied. Generally, a higher load used in the test results in a larger imprint and a more homogenous mechanical response. On the other hand, for a relatively small load, the response refers to an individual phase of the tested material (Figure 2). In this last case, the histograms of indentation properties have a multimodal distribution and it is possible to distinguish each phase. For this purpose, the deconvolution technique presented by Bobko and Ulm [19] is used.

The deconvolution procedure allows for the identification of a number of material phases and their mechanical properties from a grid indentation data set. In this approach, each indentation is treated as an independent statistical event, and the obtained values of $H_{I T}$ and $E_{I T}$ are considered as random variables. The first step is the generation of experimental cumulative distribution functions (CDF) of these variables. Next, one is specifying the theoretical CDF. It is assumed that a material is composed of $j=(1,2 \ldots n)$ phases and each phase occupies a part $f_{j}$ of the indented surface. The distribution of properties is described by Gaussian distributions, expressed by mean values $\mu_{j}^{E I T} / \mu_{j}^{H I T}$ and standard deviations $\sigma_{j}^{E I T} / \sigma j^{H I T}$ of hardness $H_{I T}$ and elastic modulus $E_{I T}$. The unknowns $\left\{f_{j}, \mu_{j}^{E I T}, \mu_{j}^{H I T}, \sigma_{j}^{E I T}, \sigma_{j}^{H I T}\right\}$ for $j=(1,2 \ldots \mathrm{n})$ are determined by minimizing the difference between the experimental and theoretical CDFs. The results of the deconvolution procedure are estimates of the mean value and the standard deviator of hardness $H_{I T}$ and modulus $E_{I T}$ for each phase.

\section{Materials and methods}

The investigated varved clay comes from close to the city of Bełchatów in central Poland. The tested material is composed of dark layers with a thickness of up to about $5 \mathrm{~mm}$ and very thin bright layers. It is presented in Figure 3 . The particle size distributions of varved clay as a unity, and the bright and dark layers separately, are presented in Table 1. The data was obtained from three different representative samples taken for each layer and the varved clay using the standard hydrometer method [20]. Classification of the 

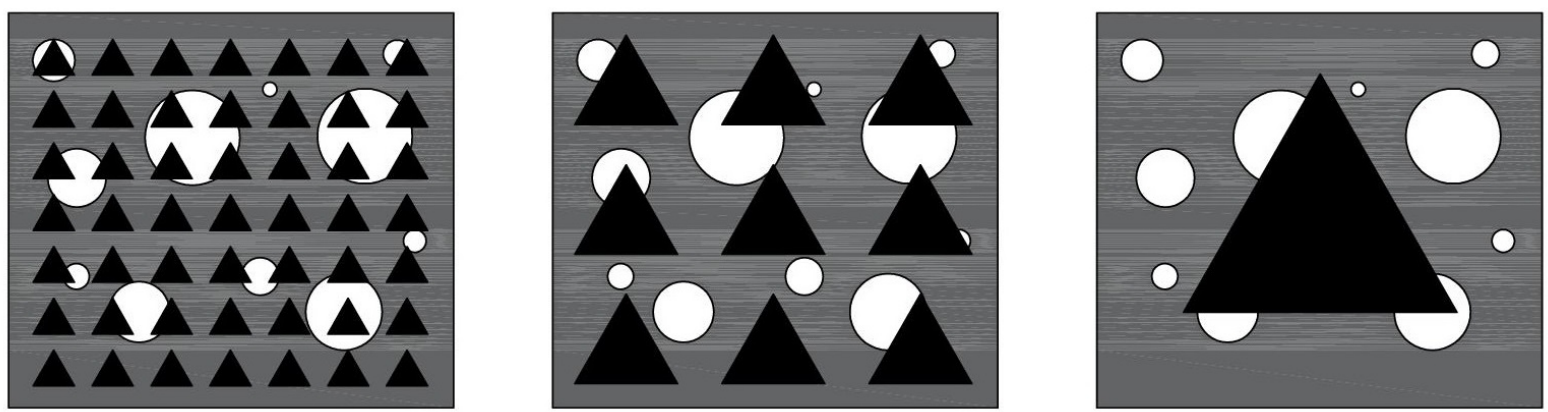

Figure 2: Scheme of the GIT for various loads.

Table 1: The fractional composition of the tested material.

\begin{tabular}{ccccc}
\hline & \multicolumn{3}{c}{ Fraction content [\%] } & Type of soil \\
\cline { 2 - 4 } & Sand 0.063-2 mm & Silt 0.002-0.063 mm & Clay $<0.002 \mathrm{~mm}$ & \\
\hline Dark layer & $0.2-0.4$ & $36.5-51.2$ & $48.6-63.1$ & $\mathrm{Cl}$ \\
Light layer & $5.7-22.9$ & $52.5-71.8$ & $18.7-24.6$ & $\mathrm{siCl} / \mathrm{sasiCl}$ \\
Varved clay & $2.4-3.6$ & $53.2-67.7$ & $28.7-44.4$ & $\mathrm{Cl} / \mathrm{siCl}$ \\
\hline
\end{tabular}

samples was conducted in accordance with [21]. The dark layers consist mainly of clay fraction $(\leq 0.002 \mathrm{~mm})$ and silt fraction (0.002-0.063 mm). The composition of bright layers is more variable, but the main fraction is silt. Due to the variability of the grain size distribution and thickness of the layers, the composition of the varved clay is also variable. The examinations of its internal structure i.e. identification of lamination, its thickness and arrangement, were presented by the author in [22].

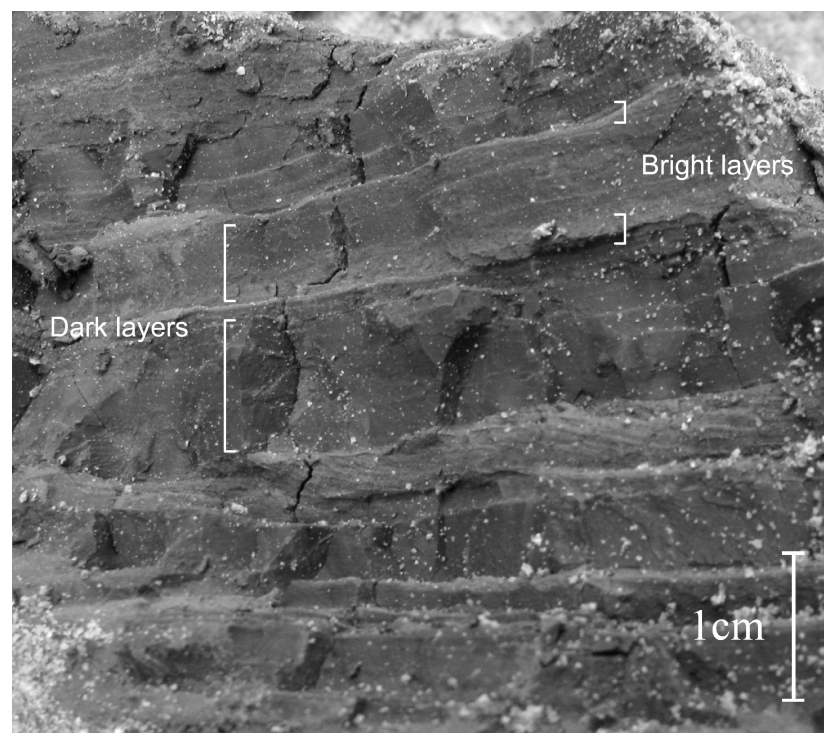

Figure 3: Varved clay.
A series of indentation tests were performed on the material. The tests were carried out using an TTX-NHT indenter (CSM Instruments) with a Berkovich diamond tip. To obtain reliable results, proper preparation of the tested surface was necessary - it must be flat, clean and smooth. The tested samples had a natural water content and the surface was perpendicular to the stratification. Due to the nature of the material and layer thickness, it was not possible to prepare the surface parallel to the lamination. Before the test, the soil was cold mounted with the use of epoxy resin and then placed in a vacuum chamber. After hardening of the resin, the samples were polished in three steps: first using 500 grit grinding paper, and additionally moistening the sample with alcohol; then with a diamond polishing cloth with a grit diameter of $15-3 \mu \mathrm{m}$ (with a diamond suspension of the grit diameter of $15 \mu \mathrm{m}$ ); and finally with a cloth with a grit diameter $\leq 3 \mu \mathrm{m}$ (with a diamond suspension of the grit diameter of $1 \mu \mathrm{m}$ ). The prepared specimen is shown in Figure 4. The samples, due to

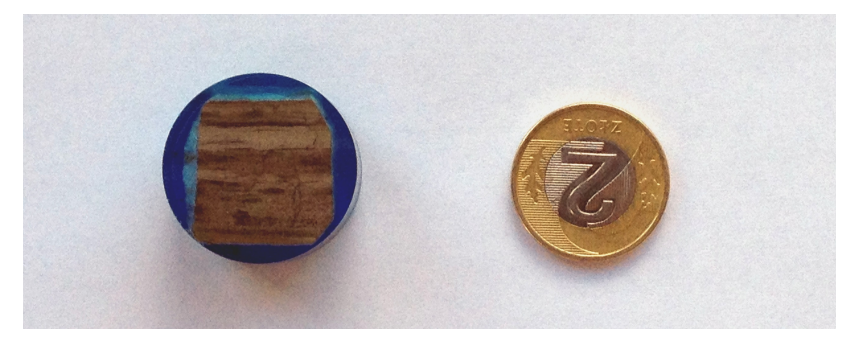

Figure 4: The sample prepared for the nanoindentation test. 
a)

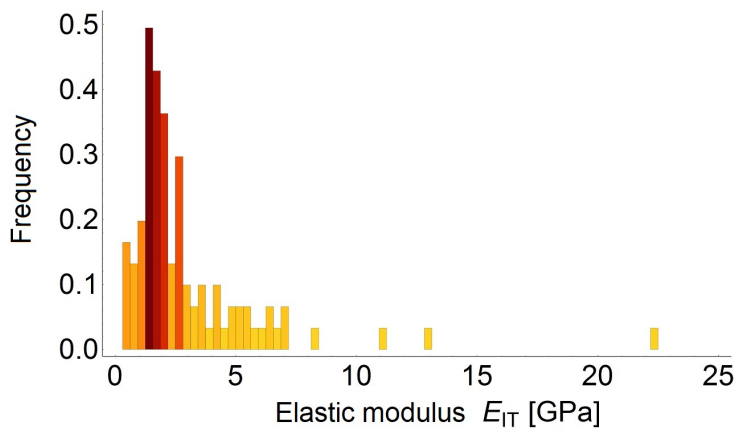

b)

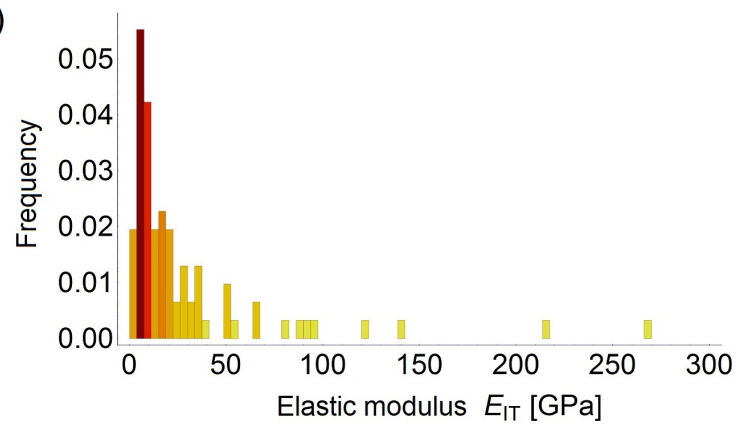

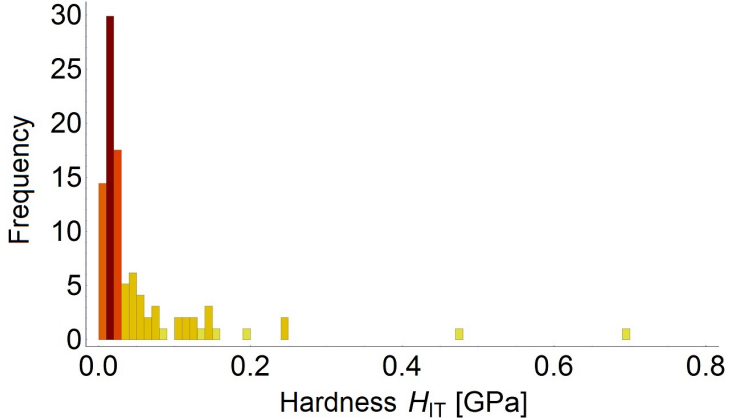

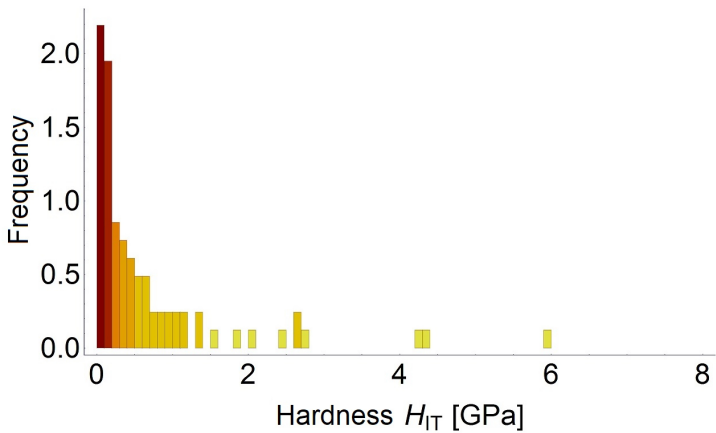

Figure 5: Histograms of elastic modulus $E_{I T}$ and hardness $H_{I T}$ for a) dark layer b) light layer.

the possibility of fracture of the soil by drying, were subjected to testing immediately after grinding.

Prior to the actual test, camera images were analyzed to identify the layering. Then, several indentations were performed in order to determine the optimum preset indentation force. After the preliminary measurements, a maximum force of $200 \mathrm{mN}$ was assumed, which resulted in an imprint in the material with a size of about 10-30 $\mu \mathrm{m}$. The size of grains and particles in the tested soil ranges from about $200 \mu \mathrm{m}$ (for sand fraction) to less than $2 \mu \mathrm{m}$ (for clay fraction). Due to this fact, selected force allowed for the determination of the mechanical parameters of the layers as a whole. The tests were carried out in two series: separately for the dark and light layers. An automatic grid of 100 indentation points was set for each layer. It was not possible to carry out more indentations in a given series due to the thickness of the layers. However, even such a number of results allowed the components of the material to be distinguished, which is shown in the next section. After the test, for each individual indentation, a P-h curve was obtained and the hardness $H_{I T}$ and elastic modulus $E_{I T}$ were determined. For the used indenter tip, the Poisson's ratio is $v_{i}=0.07$ and the elastic modulus is $E_{i}=1000$ $\mathrm{GPa}$. To calculate $E_{I T}$, it is necessary to assume a certain value of the Poisson ratio of the tested soil. However, this value, if reasonable, does not have a great impact on the determined values of the moduli. Therefore, when taking into account the mineral composition of the material, the average value of this coefficient was estimated to be 0.25 .

\section{Results}

The histograms of the established hardness $H_{I T}$ and elastic modulus $E_{I T}$ for both layers are presented in Figure 5. It shows the frequency (by means of probability density) of occurrence of the given class ranges of values. Due to unevenness of the surface, some indentations failed. For the dark layer, 97 correct measurements were obtained, and for the light layer 81 correct indentations were made. The $H_{I T}$ and $E_{I T}$ values for the bright silty-sandy layer are about 10 times greater than for the dark clayey layer. In all cases, a certain scatter of results is observed. This is the result of the fact that both layers consist of grains and particles of different sizes and properties.

In order to describe the morphology of the layers, the deconvolution technique was applied. The procedure was carried out with the assumption of one, two or three phase, respectively. The outcomes are presented in Figures 6 (for the dark layer) and 7 (for the light layer). The histograms of elastic modulus $E_{I T}$ and hardness $H_{I T}$ are presented to- 
a)
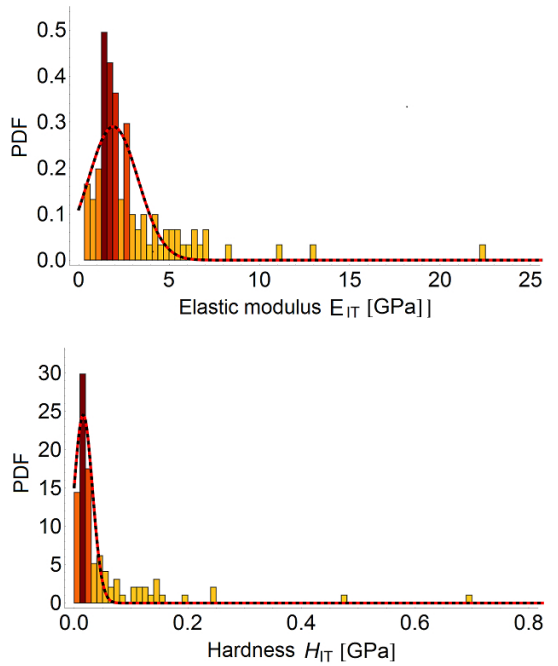

b)
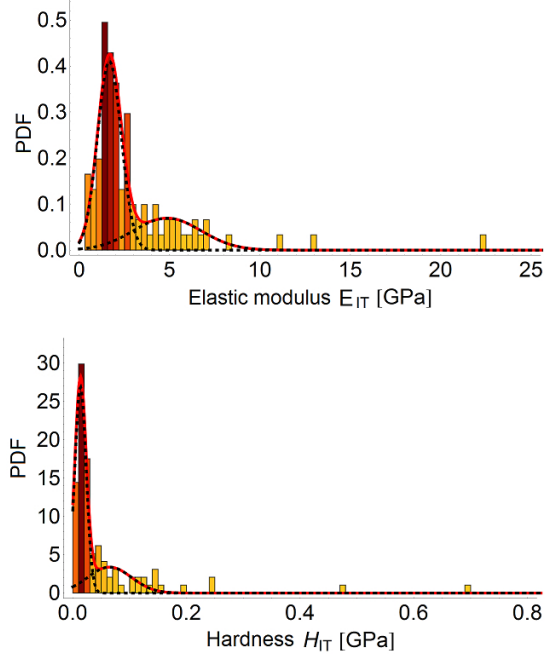

c)
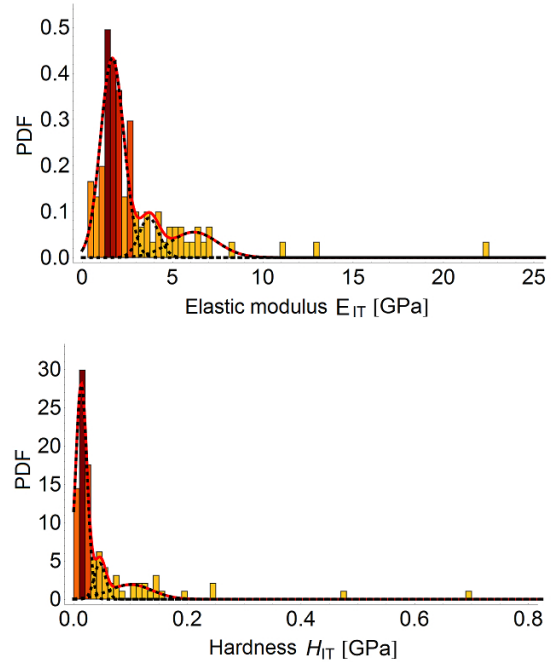
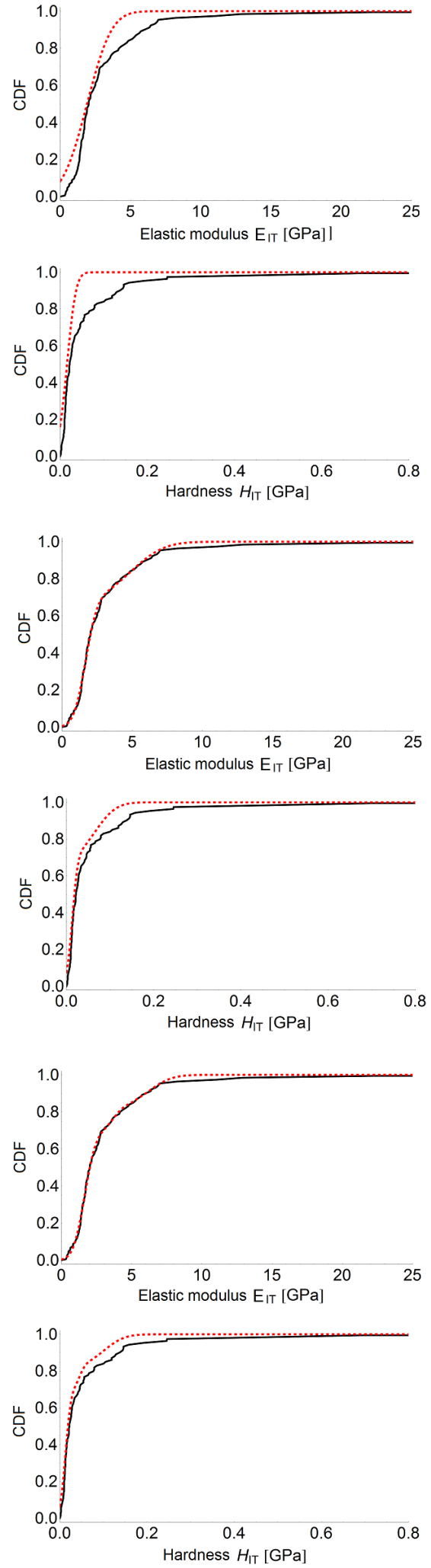

Figure 6: Results of deconvolution for a) 1 phase b) 2 phases c) 3 phases for the dark layer. The histograms of $E_{I T}$ and $H_{I T}$ with the PDF of individual phases (black dotted line) and the PDF for all phases (red continuous line), and also a comparison of theoretical (red dotted line) and experimental (black continuous line) CDFs. 
a)
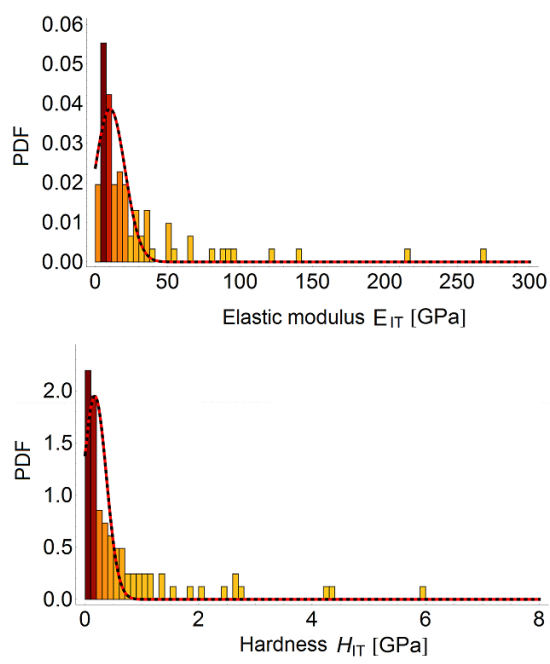

b)
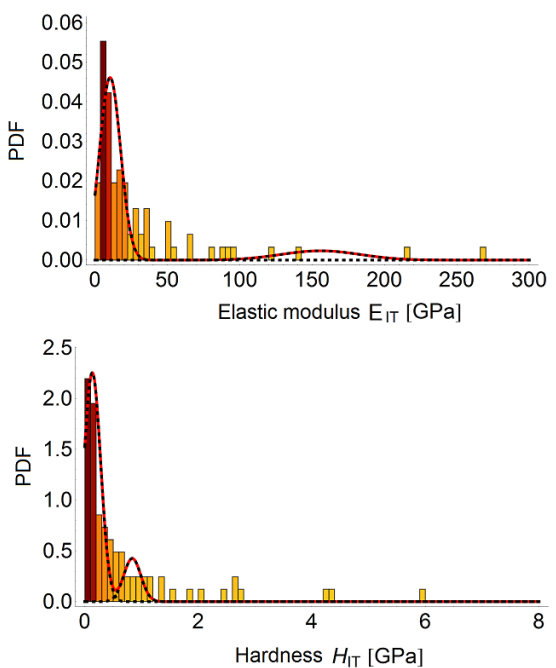

c)
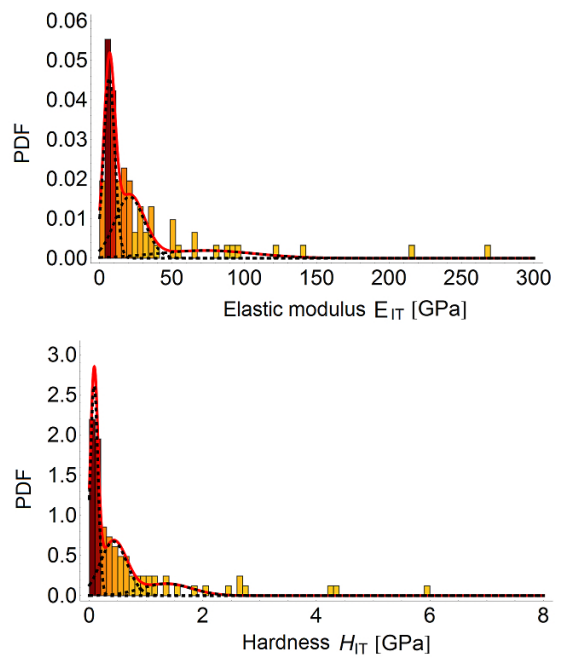
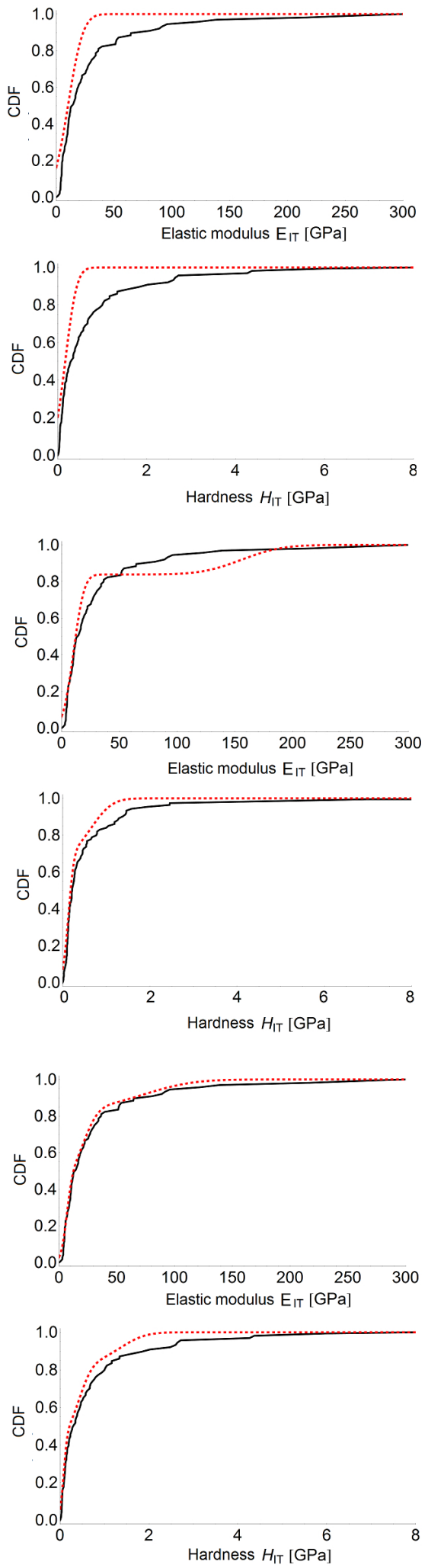

Figure 7: Results of deconvolution for a) 1 phase b) 2 phases c) 3 phases for light layer. The histograms of $E_{I T}$ and $H_{I T}$ with the PDF of individual phases (black dotted line) and the PDF for all phases (red continuous line), and also a comparison of theoretical (red dotted line) and experimental (black continuous line) CDFs. 
Table 2: Deconvolution parameters for the dark layer.

\begin{tabular}{ccccccc}
\hline \multicolumn{7}{c}{ Phases amount } \\
\hline Properties & 1 & \multicolumn{7}{c}{3} \\
\hline$\mu_{j}^{E I T}[\mathrm{GPa}]$ & 1.907 & 1.662 & 4.862 & 1.663 & 3.702 & 6.175 \\
$\mu_{j}^{H I T}[\mathrm{GPa}]$ & 0.0159 & 0.0135 & 0.0647 & 0.0133 & 0.0460 & 0.1001 \\
$\sigma_{j}^{E I T}[\mathrm{GPa}]$ & 1.376 & 0.656 & 1.874 & 0.646 & 0.548 & 1.306 \\
$\sigma_{j}^{H I T}[\mathrm{GPa}]$ & 0.0163 & 0.0100 & 0.0384 & 0.0100 & 0.0100 & 0.0378 \\
Share $[-]$ & 1 & 0.67 & 0.32 & 0.70 & 0.12 & 0.18 \\
\hline
\end{tabular}

Table 3: Deconvolution parameters for the light layer.

\begin{tabular}{|c|c|c|c|c|c|c|}
\hline \multirow[b]{2}{*}{ Properties } & \multicolumn{6}{|c|}{ Phases amount } \\
\hline & 1 & & & & 3 & \\
\hline$\mu_{j}^{E I T}[\mathrm{GPa}]$ & 10.129 & 10.373 & 155.757 & 6.629 & 20.665 & 73.020 \\
\hline$\mu_{j}^{H I T}[\mathrm{GPa}]$ & 0.1691 & 0.1311 & 0.8362 & 0.0830 & 0.4250 & 1.3570 \\
\hline$\sigma_{j}^{E I T}[\mathrm{GPa}]$ & 10.310 & 7.259 & 27.321 & 3.841 & 10.195 & 33.778 \\
\hline$\sigma_{j}^{H I T}[\mathrm{GPa}]$ & 0.2048 & 0.1486 & 0.1509 & 0.0669 & 0.2348 & 0.4427 \\
\hline Share [-] & 1 & 0.84 & 0.16 & 0.44 & 0.40 & 0.16 \\
\hline
\end{tabular}

gether with the probability density functions (PDF) of individual phases (marked by a black dotted line) and the PDF for all the phases (marked by a red continuous line). Next to them, the cumulative distribution functions (CDF) for both parameters are demonstrated. Theoretical CDFs are marked by a red dotted line, and experimental ones by a black continuous line. The comparison of the quality of approximation of the experimental CDF by a theoretical one, according to the solutions for minimizing the issue, allows the selection of an adequate amount of components for each phase number. When considering the results of deconvolution for the dark layer, it was concluded that in relation to one phase (Figure 6a), the quality of description is substantially improved for two phases (Figure $6 \mathrm{~b}$ ), which is also clearly visible in the graphs. For three phases (Figure 6c), this improvement is already insignificant. In the case of the light layer, the assumption of two phases (Figure 7b) does not significantly enhance the description when compared to one phase (Figure 7a). Nevertheless, considering three phases (Figure 7c) gives much better compliance.

The values of the established parameters i.e. surface part $f_{j}$, mean values $\mu_{j}^{E I T} / \mu_{j}^{H I T}$ and standard deviations $\sigma_{j}^{E I T} / \sigma j^{H I T}$ of hardness $H_{I T}$ and elastic modulus $E_{I T}$ for all three cases (with a different amount of assumed phases) are presented in Tables 2 (for the dark layer) and 3 (for the bright layer). For the dark layer, the mean value of the modulus for one phase is $1.907 \mathrm{GPa}$. For two phases, the mean values are $1.662 \mathrm{GPa}$ and $4.862 \mathrm{GPa}$, respectively with a $67 \%$ and $32 \%$ share of the components. For three phases, the mean value is $1.663 \mathrm{GPa}, 3.702 \mathrm{GPa}$ and $6.175 \mathrm{GPa}$ with a share of $70 \%, 12 \%$ and $18 \%$. The mean hardness $H_{I T}$ value is $0.0159 \mathrm{GPa}$ for one phase, $0.0135 \mathrm{GPa}$ and $0.647 \mathrm{GPa}$ for two phases and $0.0133 \mathrm{GPa}, 0.0460 \mathrm{GPa}$ and $0.1001 \mathrm{GPa}$ for three phases, respectively. According to these results, one weaker component, which occupies the majority of the examined surface, is observed for more than one number of constituents. For the light layer, the mean value of modulus $E_{I T}$ for one phase is $10.129 \mathrm{GPa}$. For two phases, it is $10.373 \mathrm{GPa}$ and $155.757 \mathrm{GPa}$, respectively with a $84 \%$ and $16 \%$ share of the components. For three phases, it is 6.629 $\mathrm{GPa}, 20.665 \mathrm{GPa}$ and $73.020 \mathrm{GPa}$ with a share of $44 \%, 40 \%$ and $16 \%$. The mean $H_{I T}$ value is $0.1691 \mathrm{GPa}$ for one phase, $0.1311 \mathrm{GPa}$ and $0.8362 \mathrm{GPa}$ for two phases and $0.0830 \mathrm{GPa}$, $0.4250 \mathrm{GPa}$ and $1.3570 \mathrm{GPa}$ for three phases, respectively. With these results, for more than one number of components, the presence of a much stronger component is observed, which occupies about $16 \%$ of the examined surface.

\section{Discussion}

After analyzing the outcomes of deconvolution for the dark layer, it was concluded that the best result was achieved for 2 separated phases of the material. It is related to the occurrence of only two fractions - clayey and silty - that compose this layer. According to the results for two phases, the first one covers $67 \%$ of the tested surface and corre- 
sponds to the lower values of modulus and hardness. The second one covers $32 \%$ and exhibits higher values of these parameters. This is consistent to those values obtained in the granulometric analysis. The clay fraction is found in the range of 48.6-63.1\%, and the silt fraction in the range of $36.5-51.2 \%$. It could be useful to compare the outcomes of the indentation with the mineral composition determined by X-ray diffraction, however, no such studies have been carried out.

In the case of the light layer, it was indicated that the best result was achieved for three constituents. The distinguished phases cover $44 \%, 40 \%$ and $16 \%$, respectively of the indentation surface. The phase that has the largest share corresponds to the lowest values of $E_{I T}$ and $H_{I T}$, and the one with the lowest share is associated with the highest values of the parameters. For the light layer, in the granulometric analysis, three fractions were separated, i.e. clay, silt and sand, with a content of 5.7-22.9\%, 52.5-71.8\% and $18.7-24.6 \%$, respectively. Compliance of the results is considerably lower than for the dark layer. It is related to the presence of a sand fraction (which is characterized by the highest value of elastic modulus and hardness) and its impact on the material's response in the selected scale. For the 10-30 $\mu \mathrm{m}$ imprint size, the occurrence of sand grain close to the indentation surface will result in the averaged response of the material and, as a consequence, higher values of the established parameters. It is also important that due to the different granulometric composition it was possible to obtain a different smoothness of the indentation surface, which caused more errors during the tests.

When comparing the results of the mechanical properties of the identified components, some discrepancies can be found. For the dark layer, the mean values of the mechanical properties for the weaker component are $1.662 \mathrm{GPa}$ for modulus and $0.0135 \mathrm{GPa}$ for hardness. For a stronger constituent they are $4,862 \mathrm{GPa}$ and $0,0647 \mathrm{GPa}$, respectively. For the light layer, the parameters of the two weaker components, identified with silt and clay fractions, are 6.629 and $20.665 \mathrm{GPa}$ for $E_{I T}$, and 0.0830 and 0.4250 GPa for $H_{I T}$. The values are about five times higher than those obtained for the dark layer. This is associated, as stated above, with the presence of sand grains. The elastic modulus of a component identified as a sand fraction is $73.020 \mathrm{GP}$, and the hardness is 1.3570GPa. A higher number of indentations would probably improve the findings of the deconvolution, however, due to the complexity of the material, the results will always be subject to uncertainty. It should also be noted that the effect of polishing a sample may affect the obtained results.

\section{Conclusions}

On the basis of the nanoindentation tests, the hardness and elastic modulus of the dark and bright layers of varved clay were determined. There are significant differences in the values of the micromechanical parameters obtained for the layers in the selected scale of observation. The light one, i.e. silty-sandy, has much higher properties than the clayey dark layer. Furthermore, the presented results clearly confirm the heterogeneity of the composition of varved clay. Despite the limited number of tests, a separation of components of the tested surfaces was possible. In order to describe the morphology of the layers, a deconvolution technique was applied, which allowed the determination of the share of the phases and their mechanical properties. In the case of the dark layer, the best description of the results was obtained with the assumption of two phases, and for the light layer - for three. The above findings approximately coincide with the fractional composition determined in macroscopic studies, however for the light layer these differences are greater. In addition, there are some discrepancies in the results of the mechanical properties of the identified constituents. This is due to the occurrence of coarser fractions, including grains of sand, in the bright layer. The effect of different mechanical parameters of the layer constituents are the different properties of these layers and, in consequence, the anisotropy of varved clay. It indicates a multi-scale structure of the soil and the complexity of the considered issue of its strength.

\section{References}

[1] Petterson G., Renberg I., Geladi P., Lindberg A., Lindgren F., Spatial uniformity of sediment accumulation in varved lake sediments in northern Sweden, J. of Paleolimnol., 1993, 9(3), 195208

[2] DeGroot D.J., Lutenegger A.J., Characterization by Sampling and In Situ Testing - Connecticut Valley Varved Clay, Studia Geotechnica et Mechanica, 2005, 27 (3-4), 107-120

[3] Jokinen S. A., Virtasalo J. J., Kotilainen A. T., Saarinen T., Varve microfabric record of seasonal sedimentation and bottom flowmodulated mud deposition in the coastal northern Baltic Sea, Mar. Geol., 2015, 366, 79-96

[4] Lu Y., Tan Y., Lin G., Characterization of thick varved-clayey-silt deposits along the Delaware River by field and laboratory tests, Env. Earth Sci., 69(6), 2013,1845-1860

[5] Tiljander M., Ojala A., Saarinen T., Snowball I., Documentation of the physical properties of annually laminated (varved) sediments at a sub-annual to decadal resolution for environmental interpretation. Quarter. Int., 2002, 88(1), 5-12

[6] Kohv M., Talviste P., Hang T., Kalm V., Rosentau A., Slope stability and landslides in proglacial varved clays of western Estonia, 
Geomorphology, 2009, 106(3), 315-323

[7] Ladd C. C., Wissa, A. E., Geology and Engineering Properties of Connecticut Vally Varved Clays with Special Reference to Embankment Construction, Soils Publication, 1970, 264

[8] Marko K., Tiit H., Peeter T., Volli K., Analysis of a retrogressive landslide in glaciolacustrine varved clay, Eng. Geol., 2010, 116(1), 109-116

[9] Tankiewicz M., Kawa M., Identification of anisotropic criteria for stratified soil based on triaxial tests results, Studia Geotechnica et Mechanica, 2017, 39 (3), 59-65

[10] Oliver W. C., Pharr G. M., An improved technique for determining hardness and elastic modulus using load and displacement sensing indentation experiments, J. Mat. Res., 1992, 7 (6), 15641583

[11] Cała M., Cyran K., Kawa M., Kolano M., Łydżba D., Pachnicz M., Rajczakowska M., Różański A., Sobótka M., Stefaniuk D., Stopkowicz A., Watach D., Identification of Microstructural Properties of Shale by Combined Use of X-Ray Micro-CT and Nanoindentation Tests, Proced. Eng., 2017, 191, 735-743

[12] Daphalapurkar N.P., Wang F., Fu B., Lu H., Komanduri R., Determination of Mechanical Properties of Sand Grains by Nanoindentation, Exp. Mech., 2011, 51, 719-728

[13] Zhu W., Hughes J. J., Bicanic N., Pearce C. J., Nanoindentation mapping of mechanical properties of cement paste and natural rocks, Mater. Charact., 2007, 58(11), 1189-1198
[14] Fischer-Cripps A. C., Nanoindentation, Springer, 2011

[15] Oliver, W. C., Pharr, G. M., Measurement of hardness and elastic modulus by instrumented indentation: Advances in understanding and refinements to methodology, J. Mat. Res., 2004, 19(1), 3-20

[16] Sneddon I. N., The relation between load and penetration in the axisymmetric Boussinesq problem for a punch of arbitrary profile, Int. J. Eng. Sci., 1965, 3(1), 47-57

[17] Francavilla A., Zienkiewicz O. C., A note on numerical computation of elastic contact problems, Int. J. Num. Meth. Eng., 1975, 9(4), 913-924

[18] Constantinides, G., Ulm, F. J., Van Vliet, K., On the use of nanoindentation for cementitious materials, Mater. Struct., 2003, 36(3), 191-196

[19] Bobko, C., Ulm, F. J., The nano-mechanical morphology of shale, Mech. Mater., 2008, 40(4), 318-337

[20] PKN-CEN ISO/TS 17892-4:2009, Geotechnical investigation and testing. Laboratory testing of soil. Part 4: Determination of particle size distribution.

[21] PN-EN ISO 14688: 2006, Geotechnical investigation and testing. Identification and classification of soil.

[22] Tankiewicz M., Structure investigations of layered soil - varved clay, Ann. Warsaw Univ. Life Sci. - SGGW, Land Reclam., 2016, 48(4), 365-375 